\title{
"The DEA Would Come In And Destroy You": A Qualitative Study of Fear And Unintended Consequences Emerging From Restrictive Opioid Prescribing Policies In West Virginia
}

Cara L Sedney ( $\nabla$ csedney@hsc.wvu.edu )

West Virginia University

Treah Haggerty

West Virginia University

Patricia Dekeseredy

West Virginia University https://orcid.org/0000-0001-6083-5358

Divine Nwafor

West Virginia University

Martina Angela Caretta

Lund University

Henry H. Brownstein

West Virginia University

Robin A Pollini

West Virginia University

Research Article

Keywords: opioids, pain medication, legislation, chronic pain

Posted Date: October 25th, 2021

DOI: https://doi.org/10.21203/rs.3.rs-991531/v1

License: (c) (i) This work is licensed under a Creative Commons Attribution 4.0 International License. Read Full License 


\section{Abstract}

Background: West Virginia has one of the highest rates of opioid overdose related deaths, and is known as the epicenter of the opioid crisis in the United States. In an effort to reduce opioid-related harms, SB 273 was signed in 2018, and aimed to restrict opioid prescribing in West Virginia. SB 273 was enacted during a time when physician arrests and convictions had been increasing for years and were becoming more prevalent and more publicized. This study aims to better understand the impact of the legislation on patients and providers.

Methods: Semi-structured interviews were conducted for a qualitative content analysis with 20 general practitioners and specialists practicing throughout West Virginia.

Results: Four themes emerged, 1. Fear of disciplinary action, 2. Exacerbation of opioid prescribing fear due to restrictive legislation, 3. Resulting care shifts and treatment gaps, and 4. Conversion to illicit substances. The clinicians recognized the harms of inappropriate prescribing and how this could affect their patients. Decreases in opioid prescribing were already occurring prior to the law implementation. Disciplinary actions against opioid prescribers and restrictive opioid prescribing policies contributed to prescriber fear and shifts in care that led to forced tapering and opioid under-prescribing. Providers felt that taking on patients who legitimately required opioids could jeopardize their career.

Conclusion: A wholistic and patient-centered approach should be taken by legislative and disciplinary bodies to ensure patients are not abandoned when disciplinary actions are taken against prescribers or new legislation is passed.

\section{Introduction}

The United States faces a nationwide public health crisis initially thought to be fueled by over-prescription of opioid pain relievers [1]. The rise in opioid overdose-related deaths can be outlined in three distinct waves; first prescription opioids, then involving heroin, and currently involving illicitly manufactured fentanyl [2-5]. The Centers for Disease Control and Prevention (CDC) in 2017 estimated that roughly 2.4 million Americans suffered from substance use disorders related to prescription opioid pain relievers and illicit opioids like heroin and fentanyl. From 1999 to 2018, an estimated 450,000 Americans died from overdoses involving opioid pain relievers and illicit opioids [6, 7]. Furthermore, the total economic burden of opioid misuse costs the United States approximately $\$ 78.5$ billion dollars annually, including healthcare cost, lost productivity, and opioid use disorder treatment [8].

Subsequent laws enacted by state and federal governmental bodies contributed to a rapid decline in opioid prescribing [9]. In the United States, opioid prescriptions fell by 54\% from 2012 to 2017 [10]. The decline in opioid prescribing in the United States has been applauded as a positive sign towards addressing the opioid epidemic, although increasingly, these reductions are recognized to have unintended consequences $[11,12]$. Additionally, the reasons and motivations for these changes bear examination, particularly because of inconsistent effects of legislative efforts on opioid prescribing, 
where the anticipated effects of law do not bear out in the real-world consequences [18], which raises the possibility of other drivers behind physician behavior change, such as fear [13]. Physicians have been shown to alter their behavior in relation to lawsuits and other external motivators [14]. Thus, studies assessing whether the rapid decrease in opioid prescribing stems from drivers aside from the legislative restrictions are needed.

West Virginia (WV) has one of the highest rates of opioid overdose related deaths, and has been regarded as the epicenter of the opioid crisis in the United States [15]. Several factors contribute to the high incidence of opioid-related harms in WV; these include wealth inequalities, economic depression, low educational attainment, and high rates of opioid prescription dating back to the mid-90s [16]. These opioid-related harms and increasing attention to the opioid crisis led to the passage of Senate Bill 273 (SB 273), which was signed on March 27, 2018, in an effort to limit opioid prescribing in WV. The law contains specific limits for initial and subsequent opioid prescriptions but exempts cancer patients, patients in hospice care, palliative care, residents of long term care facilities, patients receiving treatment for substance use disorder, and patients receiving on-going opioid treatment as of January 1, 2018 [17]. See Figure 1 for prescription limiting language.

In our previous work assessing changes in opioid prescribing related to SB 273 , we noted that overall prescription volume trended down during the 64 weeks prior and following law implementation, without an accompanying decrease in day's supply or first time opioid prescriptions, even though the law itself focused on limiting initial prescriptions [18]. We sought to understand these trends in this subsequent study through in-depth qualitative interviews with stakeholders, including opioid prescribers, in WV.

\section{Methods}

For our study of the newly introduced legal prescription limitation in WV, we designed a mixed methods study including interviews with opioid prescribers in WV. To address the question of the reluctance of medical providers to legally prescribe opioids to patients, we conducted a qualitative analysis of responses to the interview using content analysis.

Participants: We recruited a purposive sample of opioid prescribers between the months of March and October 2020. Inclusion criteria were: 1) licensed physician or dentist in the State of WV authorized to prescribe opioid medications (i.e., had a Drug Enforcement Administration [DEA] license) and 2) can read, write and speak English. Participants were recruited through the WV Practice Based Research Network (WVPBRN). The WVPBRN is a group of primary care clinicians and practices across the state of WV partnered with West Virginia University as a research entity [19]. Participants were selected, employing a maximum variation strategy [20], to ensure diversity in age, gender, urban/rural demographics, practice type, and race/ethnicity. Participant specialty was chosen to reflect specialty-specific contributions to the overall opioid prescription number in the state based upon prescription drug monitoring program (PDMP) data. Potential participants were emailed an introduction to the study and requested to participate. For the primary care physicians, 13 providers were contacted but did not respond, and one provider was 
contacted and declined. For specialist physicians, one provider was contacted but did not respond, and one additional was contacted and declined. All participants provided written informed consent prior to data collection relating to reasons for the study and all study protocols were approved by the West Virginia University Institutional Review Board protocol \# 1908659237.

Data Collection: Participants completed a one-time 30 to 60 minute semi-structured interview by telephone or in person. All the interviews were conducted by co-investigator PD, a research nurse trained in qualitative research, and the private interview was digitally audio recorded. Technical member checking [21] was conducted during interviews to verify accuracy with participants through clarifying questions. The interview began with a general discussion of the participant's specialty, career, and time in WV. The semi-structured interview guide consisted of open-ended questions generated by review of our previously documented quantitative opioid prescribing data trends in WV [18].

Interview questions focused on

1. Background on their medical practice

2. Experience with prescribed opioids

3. Legislation and rules impacted opioid prescribing

4. Understanding of SB 273 and impacts to practice

5. Changes in prescribing practices

6. Impact on patient care

This was the second stage of an explanatory sequential mixed methods study in which the quantitative findings were used to inform the subsequent qualitative inquiry [22]. Specifically, a "mixed methods interpretivism" approach as detailed by Howe was utilized in order to answer the "why" question of the quantitative results [23]. Participants received a $\$ 30$ gift card following participation in the study. Interviews were professionally transcribed verbatim and verified by a co-investigator (PD). The sample size was estimated to achieve data saturation [24, 25]. In qualitative research, data saturation is reached when no new themes or codes emerge from the data and provides empirical confidence that the sample size is sufficient to study the phenomenon of interest $[26,27]$.

Data Analysis: The methodological orientation underpinning this study is content analysis. Three coinvestigators (CS, PD, TH) generated the code book inductively after preliminary review of transcripts [28]. This code book included parent codes and sub-codes. Systematic line by line review of all interviews was conducted by three researchers (CS, PD, TH). The careful reading of all data documents both coinvestigators and research assistants in NVivo 12 allowed for greater reflection and iteration, as inductive codes emerged from the original list of codes. Memo-writing and group discussion by CS, PD, and TH were utilized to identify and expand themes, which were then solidified and assessed for validity by MAC and RAP [21]. The analysis continued until similar themes emerged and the team determined data saturation had been met. Then a further focus on how themes related to each other and to the quantitative study findings was conducted. An audit trail was maintained throughout data collection and analysis. Methodological rigor was enhanced by incorporating a multidisciplinary research team. 
Methodological triangulation between participants as well as investigator triangulation was used as described by Carter and colleagues for qualitative research [29]. We additionally triangulated our qualitative results with our previously published autoregressive integrated moving average (ARIMA) analysis of prescribing data for the same timeframe from the West Virginia Board of Pharmacy [18] in a sequential explanatory fashion. Reporting was cross checked with both COnsolidated criteria for REporting Qualitative research (COREQ) and Standards for Reporting Qualitative Research (SRQR) checklists for qualitative research.

\section{Results}

\section{Participant characteristics:}

Twenty individuals were interviewed consisting of 12 male and 8 female prescribers. Participants included 10 general practitioners (GPs) (primary care physician providing acute and chronic care, health education and preventative care) and 10 specialists (SP). The specialist prescriber group included three orthopedic surgeons, a pain specialist, rehabilitation specialist, general surgeon, anesthesiologist, emergency medicine physician, palliative care physician, and one dentist. Practice locations were located across the state and represented 10 different counties. The GPs' years of practice ranged from 6 to 30 years with an average of 15.3. The specialists' years of practice ranged from 10 to 31 years with an average of 17.5 years. Based upon the qualitative analysis, four themes emerged. These were: 1. Fear of disciplinary action, 2. Exacerbation of opioid prescribing fear due to restrictive legislation, 3. Resulting care shifts and treatment gaps, and 4 . Conversion to illicit substances.

\section{Findings:}

\section{Fear of disciplinary action}

SB 273 was enacted during a time when physician arrests and convictions had been increasing for years and were becoming more prevalent and more publicized. Figure 2 details some of the many investigations and disciplinary actions against physicians in the time period leading up to the enactment of SB 273, along with other societal events pertaining to opioid prescribing. Physicians under investigation had their practice interrupted, including having records confiscated and offices closed, which other physicians often became aware of anecdotally through community contacts, patients, or other providers. Often such investigations and charge filings were publicized on a local or state level, broadening the sphere of impact of the actions -these included lay news media publications, board of medicine announcements of disciplinary action, etc. Physicians were portrayed as criminals in the lay media, as in these quotes from a U.S. Attorney: "Home-grown drug dealers hidden behind the veil of a doctor's lab coat, a medical degree, and a prescription pad, are every bit as bad as the heroin dealers that flood into WV" [30] and WV Assistant Attorney General: "To the doctors, pharmacists, and other medical professionals engaged in this egregious criminal behavior across Appalachia and our country, the data in 
our possession allows us to see you and see you clearly, no matter where you are... and if you behave like a drug dealer, we will find you and ensure that the American justice system treats you like the drug dealer you are" [31]. Determination of guilt could be years after the initial investigation, and importantly, some physicians were never charged nor found guilty after having their practice interrupted with lengthy investigations.

Importantly, news coverage of such disciplinary actions against physicians included some legal and allowable practices in primary care as evidence of guilt: operating a cash-based practice, not accepting insurance, charges of "\$240 for an initial appointment and at least $\$ 160$ for each subsequent appointment", not requiring referrals, receiving patient calls on a personal cell phone, and not having special training in pain management to prescribe opioids [30].

Participants referenced multiple instances of known physicians, either in their own community or people they heard about through media or news stories, who suffered disciplinary action for opioid prescribing. Some prescribers against whom disciplinary action was taken were acknowledged to be practicing inappropriately. However, disciplinary action against these outlying prescribers resulted in fear amongst other prescribers and affected their prescribing habits, overpowering other considerations in decisions regarding prescribing. This fear was expressed by multiple participants and consequences included licensure revocation or criminal penalties related to opioid prescribing which the prescriber feared would be seen as excessive or inappropriate, even if they deemed it medically necessary. Licensing boards, the Drug Enforcement Administration, and local law enforcement were seen as enforcers. As one participant noted:

"...the fear of having your license taken away or the fear of imprisonment, or you've been burned by the DEA as someone who has been negligent, that will take over." (GP, female, 15 years of practice)

These enforcers were alerted by pharmacists or the Board of Medicine that a prescribers' practices were concerning, creating a conflicted environment between the two groups as prescribers felt like they were being policed by dispensers in their community and their medical judgement was being questioned.

"[M]ost of us noticed that whenever all of the pill mills got shut down prior to the law, it was because pharmacists were reporting the doctors who were writing too many prescriptions to the DEA and then the DEA would come and destroy you." (GP, male, 11 years of practice)

These prescribers detailed that some providers caught up in disciplinary action were viewed as "good doctors" or were practicing within what they perceived to be accepted norms of patient care. In some cases, the physicians were never charged with any crimes but could not recover after their practice had been shut down, records confiscated, or had poor publicity in the media. This resulted in a reluctance to prescribe opioids even if pain medication was perceived to be needed by patients. Another participant noted that even being "outside of the norm" of opioid prescribing was seen as high risk for disciplinary action: 
"[It] really started to scare a lot ... of providers into feeling that it wasn't worth the risk to continue to prescribe for fear of being labeled as an over prescriber or being outside of the norm or, you know, the potential liability that goes along with it." (GP, male, 14 years of practice)

These actions created an atmosphere of fear amongst prescribers which, according to one prescriber, preceded restrictive prescribing laws in WV and rendered these subsequent actions unnecessary.

"They were coming in and busting a lot of docs and then making it so... that we didn't need that law to be afraid." (GP, female, 11 years of practice)

Importantly, this temporal association (reactionary fear of prescribing opioid medications to patients based upon disciplinary action before SB 273) correlates to our previously published quantitative findings of opioid prescribing trends in WV, which documented consistent declines in opioid prescribing that preceded the implementation of the 2018 law [18].

\section{Opioid legislation exacerbated prescriber fear}

In addition to disciplinary actions against prescribers, numerous other instructions, guidelines, and regulations impacted the prescribing of opioid medication leading up to the enactment of SB 273 (Figure 2). The CDC created prescribing guidelines for opioid medication in March 2016 [32], and the WV Board of Medicine also created opioid guidelines in 2017 [33], both with the focus of curtailing inappropriate prescribing. The state of WV also created an "Opioid Response plan" in January 2018 [34] to handle what was perceived as inappropriate prescribing of opioids. As a result, nearly all participants noted that prescribing of opioids, both their own habits and what they observed in their community and amongst their partners, evolved towards moderation over time as knowledge of opioid-related harms increased. This is supported by our earlier work assessing opioid prescribing practices in the 64 weeks before and after SB 273 was implemented, demonstrating a decreasing trend throughout the entire period before the law [18]. Furthermore, our assessment of key requirements of SB 273, such as duration of opioid prescriptions, demonstrated no change in relation to SB 273 - however, over the duration of our study, the days' supply of medication decreased from 13.9 days to 7.9 and 7.3 days prior to law signing and enactment respectively, making current clinical practice at the time of law signing and enactment already in line with the 7 day prescribing limit of new opioid prescriptions for SB 273 [18].

SB 273, while implemented to address opioid over-prescribing, was viewed as exacerbating the fear already being experienced by prescribers, and for which prescribers had already changed their practice. As a result, many participants felt that the law had minimal impact because most prescribers had already curtailed opioid prescribing. However, participants noted that this law prompted further, more extreme changes in practice amongst physicians who otherwise felt they were practicing appropriately, such as cessation of all opioid prescribing. The prevailing view of participants was that all of the outlying or "irresponsible" prescribers had already been dealt with prior to SB 273. The law led many prescribers to further curtail opioid prescriptions, and in some cases, refuse to prescribe any controlled substance including medications like gabapentin (Schedule 5). 
"[SB 273] ended up affecting mostly the responsible prescribers of opioids. The people who were already doing due diligence ended up being the ones who were concerned about the law because all the irresponsible prescribers I think were already getting obliterated." (GP, male, 11 years of practice)

A "chilling effect" instigated by fear of disciplinary action and exacerbated by SB 273 created a dearth of prescribers willing to provide opioid prescriptions within entire communities as it was considered to be increasingly risk-laden. This occurred even as the need for opioid medication was recognized within the prescriber community. The enormity of the need was recognized by prescribers even as they did not feel capable of meeting it themselves:

"Almost all prescribers in WV cut it back, a few that still do it, really do so at great risk to themselves. I think the law that occurred in 2018, really, if anything shifted us to a place where there's not enough opioid prescribing for many painful conditions that aren't treatable with other means." (GP, male, 11 years of practice)

The change was noted among prescribers across practice types and locations and included patients with cancer-related pain or those which were taking opioids prior to the January 1,2018 , both populations which were specifically excluded by the law.

"There was a dramatic reduction in the number of physicians in the area who were writing anything controlled. It didn't matter if it was a schedule 2 or a schedule 5 . They just said, "No, I'm not going to do this. I'm not putting my license on the line." (GP, female, 10 years of practice)

\section{Care shifts and treatment gaps resulted from disciplinary actions and legislation}

The fear created by disciplinary actions against other prescribers and exacerbated by SB 273 led to refusal by some prescribers to continue prescribing opioid medications; this created care shifts and treatment gaps, particularly for chronic pain patients. This, again, is supported by our prior quantitative findings [18]. While first time opioid prescriptions and days' supply, which were the specific focus of SB 273 , did not change in relation to the law, overall prescription numbers decreased, demonstrating a differential impact on continuing opioid medications. Participants described these care shifts and treatment gaps as negatively affecting patient care, as patients could not access continued opioid medication for their chronic conditions. Prescribers detailed a chaotic in-flooding of patients left with no prescriber for their opioid medications after disciplinary action against some physicians or prescribing cessation as a result of the law, and this care shifted to remaining physicians in the community. These patients either shifted to other primary care physicians, specialty pain physicians, or were in effect forcibly tapered.

"Every time a physician is raided or arrested, we get several hundred referrals of those patients who are, either appropriately, or inappropriately on opioids that we have to sort out." (Specialist, male, over 30 years of practice) 
Treatment gaps in chronic opioid management represented de facto patient abandonment amongst prescribers who stopped prescribing due to fear of disciplinary action in light of the new legislation. Some general practice physicians refused to treat chronic pain completely. Often these patients were in effect forcibly tapered or transferred to outlying specialty pain clinics in faraway locations. Participants describe patients attempting to change physicians after their own physician refused to continue writing chronic opioids with only a week's worth of medications or enough medication to get them to the date of the specialist clinic visit. Specialists noted an increase in patient referrals requesting to take over longterm opioid management for their chronic pain after their primary care physicians refused upon passage of SB 273. Primary care participants noted that these patients were a stretch on already tenuous rural clinic capacity due to the number of patients and the level of management required.

"When these prescribers were shut down by the, either Board of Medicine or the DEA, we had to pick up the pieces as other local physicians-- well, we would get an influx of patients from these doctors each time" (GP, male, 30 years of practice)

\section{Conversion to illicit substances}

The perception of many prescriber participants was that patients who were left without opioids, either from provider refusal due to fear of disciplinary action and restrictive opioid legislation, or from disciplinary action against the provider causing abrupt lack of care, transitioned to illicit substances such as heroin. One participant related direct experience with patients as they later presented in a clinical capacity asking for help with their substance use disorder, and another physician related that he obtained his X-waiver purely to meet the patient need of those whom had been forcibly tapered off of chronic opioid medication.

"[T]hey show up at my door a year later, using heroin for a year... saying, 'I need help.' And I said, 'Well, what happened?' 'Well, I was getting a legitimate prescription, and then they stopped...' And it's definitely, honestly, it's a lot more now than what it was before this legislation." (GP, male, 14 years of practice)

Participants noted that these patients often directly related this transition to changes in the availability of prescribed opioids for chronic pain. The participants felt that these care gaps and unintended consequences were created by disciplinary actions taken against physicians without considering the impact on the patients receiving chronic opioid medication.

"That was a big problem and a big oversight on behalf of law enforcement and the physician community... We didn't have a good plan when we got these doctors down. We didn't- we didn't go in and find all these patients and... pick up the pieces from these patients. So that we could appropriately taper them and in a way that managed ... their withdrawal symptoms and their dependency without them turning to the illicit market. And I think that's a big source of a lot of our problems." (GP, male, 30 years of practice) 
Participants recognized that these unintended effects were understudied, but have had potentially significant effects on communities in WV.

\section{Discussion}

Opioid over-prescribing is widely recognized as playing a critical role in the genesis of the opioid crisis. However, while the clinicians we interviewed recognized the harms of inappropriate prescribing and acknowledged that this affected their patients, they felt that decreases in opioid prescribing were already occurring prior to the law implementation in 2018. A decrease in opioid prescribing prior to law implementation was also seen in our quantitative data analysis [18]. This also appears consistent with other's quantitative data, as Sutherland and colleagues note a decrease in opioid dispensing after surgery related to the 2016 CDC guidelines on opioid prescribing [35], and Ranapurwala and colleagues noted a similar decline after state-level Board of Medicine opioid prescribing limitation policy [36]. In our sample, fear of disciplinary action was frequently cited as a motivator to curtail or completely cease opioid prescribing.

The possibility of other factors besides restrictive opioid prescribing laws driving the decrease of opioidrelated prescribing is supported in the marginal impact of such laws in various analyses. In our ARIMA analysis of SB 273, we found a decrease of overall opioid prescriptions without an accompanying decrease in first time prescriptions or days' supply, even though they were the main foci of the law [18]. Minimal or inconsistent impact was also seen by a variety of other groups employing a variety of other quantitative analyses [37-39]. Prior to these relatively recent legislative attempts, prescription drug monitoring programs were initiated with the same goal. Several studies have reported reducing availability of controlled substances with physician utilization of prescription drug monitoring programs [40-42]; however again the effects varied by state [43].

The clinicians we interviewed describe a reactionary process whereby despite the good intent of such restrictive laws, patients who need opioid medications for pain management may not get them due to prescriber fear of disciplinary action. This contributed to patient abandonment, in situations where they had already curtailed any inappropriate prescribing prior to implementation of the law. The downstream effects of the under-prescribing or sudden reduction in access to opioid treatment due to prescriber fear of disciplinary action in WV may have driven unintended consequences. Such unintended consequences are the subject of recent study, with links related to undertreated pain, increasing experienced stigma amongst pain patients, [11] and increased overdose risk amongst patients [12]. On an economic level, some researchers estimate that undertreatment of pain may lead to loss of productivity costing the United Sates as much as 299 billion dollars annually [44]. Our participants related care gaps and forced tapering as a result of SB 273, similar to that reported by Dickson-Gomez and colleagues as unintended consequences of PDMP implementation in various states [45]. The idea that such supply-side restrictions on prescribed opioids may drive illicit use and opioid related deaths has also been explored and supported in a further quantitative analysis by Kim [46]. 
There is little existing literature regarding the effect of fear of disciplinary actions upon prescriber behavior, but it may be understood in the context of "defensive medicine" which is defined as "a physician's deviation from what is considered to be good practice to prevent complaints" [47]. Qualitative analysis of defensive medicine practices has noted that "positive defensive medicine changes" such as increased diagnostic work, referrals, or time spent counselling or consenting patients is not related to a specific enforcement event, but that "negative defensive medicine changes" such as "withdrawal from the doctor-patient relationship and particular fields of practice" were related to specific complaints or enforcement events [48]. Our data supports this assertion since the prescribers interviewed in this study stated that litigation or criminal actions against physicians in high-profiled cases led to some prescribers to stop opioid prescription altogether.

Some limitations exist in this study. Like other qualitative interview-based studies, desirability bias may play a role in our physician interviews. Doctors often referred to others instead of themselves, which may have misrepresented their own thoughts or experiences. In particular, the influence of fear on practice pattern changes was often referenced in terms of "other providers" but may in fact be a reflection of the influence of fear on the participant physician's own practices. We utilized a variety of techniques to ensure validity and reliability of our results [21]. Our number of interviews $(N=20)$ enabled both diversity of narrative and also theme saturation, while our sampling plan enabled a broad assessment across prescriber demographics, specialty, location, and practice type. Although we recruited with an eye towards diversity and achieved thematic saturation, the findings do not apply to all providers in WV and may not apply to other states with different demographics. We utilized a mixed methods interpretive approach to explain quantitatively measured effects of state-level legislation on prescribing habits as published in an earlier study [18]. Additionally, we utilized both methodological and investigator triangulation to limit bias of the interpretation of data [29].

Importantly, this study reports on the physician perceptions of the cause and effect of changing opioid prescribing habits and unintended consequences. It is imperative that future work investigate the direct effect of these trends on patient care and outcomes.

\section{Conclusions}

Disciplinary actions against opioid prescribers and restrictive opioid prescribing policies in WV contributed to prescriber fear and shifts in care that led to forced tapering and opioid under-prescribing. Prescribers report concern that taking care of these orphan patients would put their own careers at risk. A wholistic and patient-centered approach should be taken by legislative and disciplinary bodies to ensure care gaps are addressed when disciplinary actions are taken against prescribers or new legislation is passed.

\section{Abbreviations}

ARIMA- autoregressive integrated moving average 
CDC- The Centers for Disease Control and Prevention

COREQ- COnsolidated criteria for REporting Qualitative research

DEA- Drug Enforcement Administration

GP-general practitioners

PDMP- prescription drug monitoring program

SB 273- Senate Bill 273

SP- specialists

SRQR-Standards for Reporting Qualitative Research

WVPBRN- West Virginia Practice Based Research Network

\section{Declarations}

\section{Ethics approval and consent to participate}

The Institutional Review Board of West Virginia University approved this study.

\section{Consent for publication}

Not applicable

\section{Availability of data and materials}

Data used for this study can be accessed upon request from the Principal Investigator (Dr. Cara Sedney) at csedney@hsc.wvu.edu

\section{Competing interests}

The authors declare that they have no competing interests.

\section{Funding}

This study is part of the main 1R21DA049861-01 study, which was funded by the National Institute on Drug Abuse. The funders had no role in the study design, data collection and analysis, nor any preparation of any content of the manuscript.

Research reported in this publication was supported by the National Institute of General Medical Sciences of the National Institutes of Health under Award Number 5U54GM104942-04. The content is solely the 
responsibility of the authors and does not necessarily represent the official views of the National Institutes of Health.

\section{Authors' Contributions}

This study was led by CS and TH who were key contributors to study design, analysis, drafting and writing of the article. PD assisted with data analysis and drafting of the article as well as administrative support for the study. DN contributed to drafting the article, editing, and research. MC led the qualitative analysis and supervised the graduate student team. HB contributed to drafting the article, study design, and editing. RP contributed to drafting and writing of the article and provided expert input into study design. All authors have read and approved the version to be published.

Acknowledgments: The authors would like to thank Rachael Hood and Brandon Rothrock, graduate students at WVU for their expertise and assistance with the coding of the data.

\section{References}

1. Lyden J, Binswanger IA. The United States opioid epidemic. Vol. 43: Seminars in Perinatology. W.B. Saunders; 2019. pp. 123-31.

2. Centers for Disease Control and Prevention. Vital signs: overdoses of prescription opioid pain relievers-United States, 1999-2008. MMWR Morb Mortal Wkly Rep. 2011;60(42):1487-92.

3. Rudd R, Paulozzi L, Baur M, Burleson R, Carlson R, Dao D, et al. Increases in heroin overdose deaths28 states, 2010 to 2012. MMWR Morb Mortal Wkly Rep. 2014;63(39):849.

4. Gladden RM, Martinez P, Seth P. Fentanyl law enforcement submissions and increases in synthetic opioid-involved overdose deaths-27 states, 2013-2014. MMWR Morb Mortal Wkly Rep. 2016;65:837-43.

5. O'Donnell JK, Halpin J, Mattson CL, Goldberger BA, Gladden RM. Deaths involving fentanyl, fentanyl analogs, and U-47700-10 states, July-December 2016. MMWR Morb Mortal Wkly Rep. 2017;66:1197-202.

6. Centers for Disease Control and Prevention. Wide-ranging online data for epidemiologic research (WONDER) [Internet]. National Center for Health Statistics. 2020 [cited 2021 Mar 2]. Available from: http://wonder.cdc.gov.

7. Substance Abuse and Mental Health Services Administration (SAMHSA). 2017 NSDUH Annual National Report [Internet]. 2018. Available from: https://www.samhsa.gov/data/report/2017-nsduhannual-national-report.

8. Florence CS, Zhou C, Luo F, Xu L. The economic burden of prescription opioid overdose, abuse, and dependence in the United States, 2013. Med Care. 2016;54(10):901-6.

9. Griffith KN, Feyman Y, Auty S, Crable EL, Levengood T. County-level data on U.S. opioid distributions, demographics, healthcare supply, and healthcare access. Data Br. 2021;35(106779). 
10. Owens B. Opioid prescriptions down but some patients fear doctors now too strict. Can Med Assoc J. 2019;191(19):E546-7.

11. Benintendi A, Kosakowski S, Lagisetty P, Larochelle M, Bohnert A, Bazzi A. "I felt like I had a scarlet letter": Recurring experiences of structural stigma surrounding opioid tapers among patients with chronic, non-cancer pain. Drug Alcohol Depend. 2021;222(108664):Epub 2021 Mar. $18 .$.

12. Mueller SR, Glanz JM, Nguyen AP, Stowell M, Koester S, Rinehart DJ, et al. Restrictive opioid prescribing policies and evolving risk environments: A qualitative study of the perspectives of patients who experienced an accidental opioid overdose. Int J Drug Policy. 2021;92(103077):Epub 2021 Jan $8 .$.

13. Steimer T. The biology of fear- and anxiety-related behaviors. Dialogues Clin Neurosci. 2002;4(3):231-49.

14. Kessler DP. Evaluating the medical malpractice system and options for reform. J Econ Perspect. 2011;25(2):93-110.

15. Centers for Disease Control and Prevention. Drug overdose deaths [Internet]. 2019 [cited 2019 Aug 21]. Available from: https://www.cdc.gov/drugoverdose/data/statedeaths.html.

16. Merino R, Bowden N, Katamneni S, Coustasse A. The Opioid Epidemic in West Virginia. Health Care Manag (Frederick). 2019;38(2):187-95.

17. Opioid Reduction Act. West Virginia Legislature; p. § 54, 2018.

18. Sedney CL, Khodaverdi M, Pollini R, Dekeseredy P, Wood N, Haggerty T. Assessing the impact of a restrictive opioid prescribing law in West Virginia. Subst Abus Treat Prev Policy. 2021;16(1).

19. West Virginia Clinical and Translational Science Institute. West Virginia Practice-Based Research Network [Internet]. [cited 2021 Mar 30]. Available from: https://www.wvctsi.org/programs/community-engagement-outreach/practice-based-researchnetwork/.

20. Creswell JW. Qualitative inquiry and research method: Choosing amoung five approaches. 2nd ed. Thousand Oaks: SAGE Publications; 2007.

21. Cho J, Trent A. Validity in qualitative research revisited. Qual Res. 2006;6(3).

22. Ivankova N, Creswell JW, Stick S. Using mixed-methods sequential explanatory design: From theory to practice. Field methods. 2006;18(1):3-20.

23. Howe KR. Mixed, Methods. Mixed Causes? Qual Inq. 2011;17(2).

24. Sandelowski M. Sample size in qualitative research. Res Nurs Heal. 1995;18(2):179-83.

25. Lincoln YS, Guba, Egon G. Naturalistic inquiry. Newbury Park: SAGE Publications; 1985. 235 p.

26. Guest G, Bunce A, Johnson L. How Many Interviews Are Enough?: An Experiment with Data Saturation and Variability. Field methods. 2006;18(1):59-82.

27. Fusch PI, Ness LR. Are We There Yet? Data Saturation in Qualitative Research. Qual Rep [Internet]. 2015;20(9):1418-1416. Available from: https://nsuworks.nova.edu/tqr/vol20/iss9/3/. 
28. Saldana J. The Coding Manual for Qualitative Researchers. 3rd ed. London: SAGE Publications; 2016.

29. Carter N, Bryant-Lukosius D, DiCenso A, Blythe J, Neville AJ. The use of triangulation in qualitative research. Oncol Nurs Forum. 2014;41(5):547-7.

30. Raby J. Doctors Charged in West Virginia, Virginia Pill Mill Case [Internet]. West Virginia Public Broadcasting News. 2018 [cited 2021 Jun 19]. Available from:

https://www.wvpublic.org/news/2018-02-21/doctors-charged-in-west-virginia-virginia-pill-mill-case.

31. Flatley J. Federal charges filed against 11 doctors in Appalachian opioid sting [Internet]. Metro News. 2019 [cited 2021 Jul 6]. Available from: https://wvmetronews.com/2019/09/24/federal-chargesfiled-against-13-individuals-in-appalachian-opioid-sting/.

32. Centers for Disease Control and Prevention (CDC). CDC Guideline for Prescribing Opioids for Chronic Pain - United States, 2016. MMWR Morb Mortal Wkly Rep. 2016;65(1).

33. State of West Virginia Board of Medicine. Policy on the Chronic Use of Opioid Analgesics [Internet]. Adopted as policy by the Federation of State Medical Boards April 2017. 2017. Available from: file:///C:/Users/pld0006.HS/Documents/SCI Disparities by insuranceinterviews/Guidelines_for_the_Chronic_Use_of_Opioid_Analgesics_in_Patient_Care.pdf.

34. WVDHHR. Proposed Opioid Response Plan Released for Public Comment [Internet]. 2018 [cited 2021 Jul 26]. Available from: https://dhhr.wv.gov/News/2017/Pages/Proposed-Opioid-Response-PlanReleased-for-Public-Comment-.aspx.

35. Sutherland TN, Wunsch H, Pinto R. Association of the 2016 US Centers for Disease Control and Prevention Opioid Prescribing Guideline With Changes in Opioid Dispensing After Surgery. JAMA Netw Open. 2021;4(6):e2111826.

36. Ranapurwala S, Ringwalt CL, Pence BW, Schiro S, Fulcher N, McCort A, et al. State Medical Board Policy and Opioid Prescribing: A Controlled Interrupted Time Series. Am J Prev Med. 2021;60(3):34351.

37. Agarwal S, Bryan JD, Hu H, Lee JS, Chua K, Haffajee RL, et al. Association of state opioid duration limits with postoperative opioid prescribing. JAMA Netw Open. 2019;12(2):1-11.

38. Sacks DW, Hollingsworth A, Nguyen T, Simon K. Can policy affect initiation of addictive substance use? Evidence from opioid prescribing. J Health Econ. 2021;76:102397.

39. Oueini R, Goodin A, Vouri SM, Park H, Lo-Ciganic W-H, Hincapie-Castillo JM. Changes in Schedule II oral opioid volume dispensed in a private health plan following Florida's Acute Pain Opioid Restriction Law. J Manag Care Spec Pharm. 2021;27(6):779-84.

40. Patrick SW, Fry CE, Jones TF, Buntin M. Implementation Of Prescription Drug Monitoring Programs Associated With Reductions In Opioid-Related Death Rates. Health Aff. 2016;35(7).

41. Strickler GK, Kreiner P, w, Halpin JF, Doyle E, Paulozzi LJ. Opioid Prescribing Behaviors - Prescription Behavior Surveillance System, 11 States, 2010-2016. MMWR Surveill Summ. 2020;69(1).

42. Bao Y, Pan Y, Radakrishnan S, Luo F, Pincus HA, Schackman BR. Prescription Drug Monitoring Programs Are Associated With Sustained Reductions In Opioid Prescribing By Physicians. Health Aff. 
2016;35(6).

43. Brady JE, Wunsch H, DiMaggio C, Lang BH, Giglio J, Li G. Prescription drug monitoring and dispensing of prescription opioids. Public Health Rep. 2014;139-47.

44. Page R, Blanchard E. Opioids and Cancer Pain: Patients' Needs and Access Challenges. J Oncol Pract. 2019;15(5):229-31.

45. Dickson-Gomez J, Christenson E, Weeks M, Galletly C, Wogen J, Spector A, et al. Effects of Implementation and Enforcement Differences in Prescription Drug Monitoring Programs in 3 States: Connecticut, Kentucky, and Wisconsin. Subst Abus. 2021;15(1178221821992349).

46. Kim B. Must-access prescription drug monitoring programs and the opioid overdose epidemic: The unintended consequences. J Health Econ. 2021;75(102408).

47. Toker A, Shvarts S, Perry ZH, Doron Y, Reuveni H. Clinical guidelines, defensive medicine, and the physician between the two. Am J Otolaryngol. 2004;25(4):245-50.

48. Cunningham W, Dovey S. Defensive changes in medical practice and the complaints process: a qualitative study of New Zealand doctors. N Z Med J. 2006;119:1244.

49. West Virginia Legislature 2018 Regular Session. Enrolled Committee Substitute for Committee Substitute for Senate Bill 273 [Internet]. 2018 [cited 2021 Apr 1]. p. 21-2. Available from: http://www.wvlegislature.gov/Bill_Text_HTML/2018_SESSIONS/RS/bills/SB273 SUB2 ENR.pdf.

\section{Figures}

\$16-54-4. Opioid prescription limitations.
When issuing a prescription for an opioid to an adult patient seeking treatment in an
emergency room for outpatient use, a health care practitioner may not issue a prescription for
more than a four-day supply.
(b) When issuing a prescription for an opioid to an adult patient seeking treatment in an
urgent care facility setting for outpatient use, a health care practitioner may not issue a
prescription for more than a four-day supply: Provided, That an additional dosing for up to no
more than a seven-day supply may be permitted, but only if the medical rationale for more
than a four-day supply is documented in the medical record.
(c) A health care practitioner may not issue an opioid prescription to a minor for more than a
three-day supply and shall discuss with the parent or guardian of the minor the risks
associated with opioid use and the reasons why the prescription is necessary.
(d) A dentist or an optometrist may not issue an opioid prescription for more than a three-day
supply at any time.
(e) A practitioner may not issue an initial opioid prescription for more than a seven-day
supply. The prescription shall be for the lowest effective dose which in the medical judgement
of the practitioner would be the best course of treatment for this patient and his or her
condition.

\section{Figure 1}

Prescription limitation language in SB273 (Opioid Reduction Act) [49] 


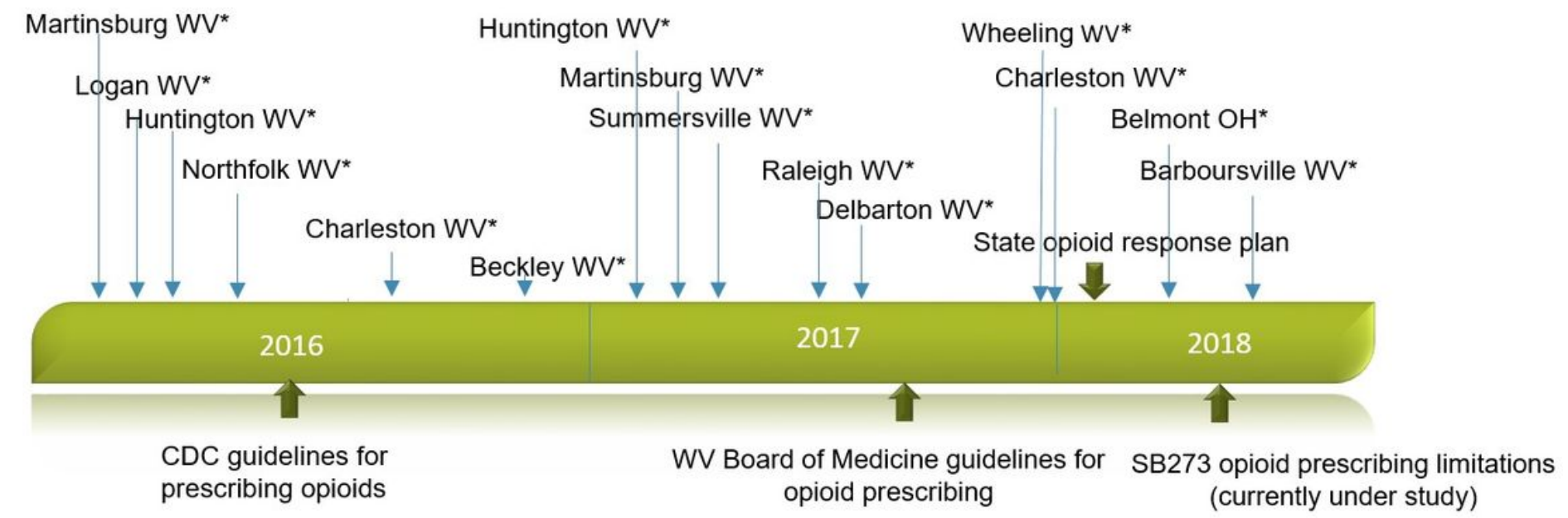

* Disciplinary action towards prescribers in the news

Figure 2

Timeline of Opioid Prescribing Influences 